\title{
LC FILTER FOR HIGH ACCURACY AND STABILITY DIGITAL MPS AT PLS *
}

\author{
S. C. Kim ${ }^{\#}$, K. M. Ha, J. H. Choi, and J. Y. Huang, Pohang Accelerator Laboratory (PAL), Korea
}

Abstract

High accuracy and stability digital controlled power supply for magnet (DigCon-MPS) is developed at PLS. This power supply has three sections. The first section is digital controller including DSP\&FPGA and precision $\mathrm{ADC}$, the second section consists of IGBT driver and four quad IGBT switch, and the third section is LC output filter section. AC input voltage of power supply is 3phase $21 \mathrm{~V}$, output current is $0 \sim 150 \mathrm{~A}$ dc. Switching frequency of four quad IGBT switch is $25 \mathrm{kHz}$. The output current of power supply has very high accuracy of $100 \mu \mathrm{A}$ step resolution at full range and the stability of $+/-1.5 \mathrm{ppm}$ for short term and +/- $5 \mathrm{ppm}$ for long term. This paper describes characteristics of filter and output current performance improvement after LC output filter at four quad digital power supplies.

\section{INTRODUCTION}

In the PLS Storage Ring (SR), more than 200 units of uni-polar and bi-polar high precision magnet power supplies (MPS's) have been operated since 1994. The unipolar MPS's are 12-step SCR rectifier type, and the bipolar MPS's are H-bridge chopper type than adopt IGBT's. Also, 144 units of transistor linear-type shunt controller for the BBA (Beam-Base Alignment) application were added in 1997. Digital controlled bipolar MPS is developed to improvement SR beam orbit feedback performance.

\section{LC OUTPUT FILTER FOR DIGITAL CONTROLLED MAGNET POWER SUPPLY}

\section{H-bridge chopper type Bi-polar MPS}

Fig. 1 shows H-bridge chopper type bi-polar MPS (HB-Chop-B-MPS) . DC output voltage is supplied as DClink input voltage of switching circuit. Switching circuit is consists H-type bridge connection. In case of need positive current supply at magnet, Q1 and Q3 are turn on simultaneously, and output current is controlled by turn on time of Q1 and Q3. In case of need negative current supply at magnet, Q2 and Q4 are turn on simultaneously, and output current is controlled by turn on time of Q2 and Q4. H-B-Chop-MPS's switching frequency is $3 \mathrm{kHz}$. This type MPS is simple in construction but switching noise is supplied to magnet. Therefore magnet is appeared noise spectrum associated with switching frequency, and these noise spectrums produce a bad effect at beam correction. Fig 2 shows frequency spectrum for output current of $\mathrm{H}-$

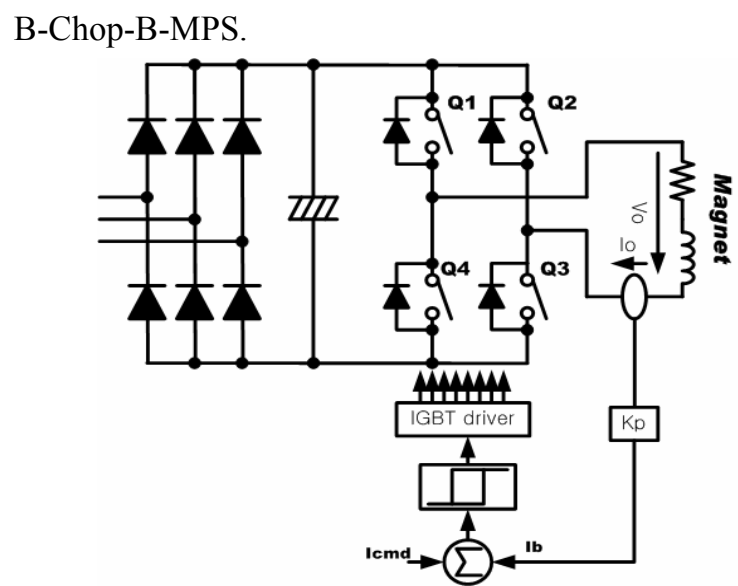

Figure 1: H-bridge chopper type bi-polar MPS.

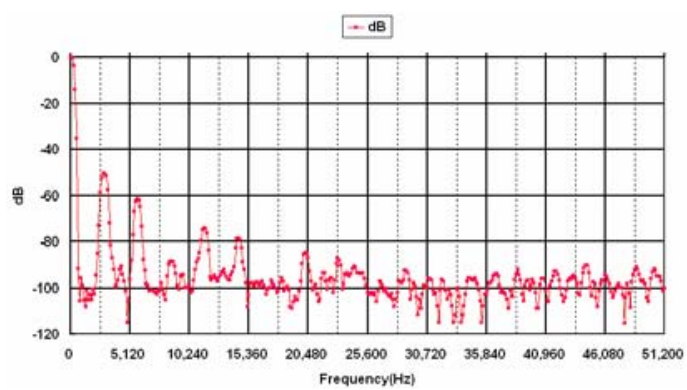

Figure 2: Frequency spectrum for output current of $\mathrm{H}$ bridge chopper type bi-polar MPS.

\section{DigCon-MPS}

Fig. 2 shows digital controlled bi-polar MPS. Main circuit configuration is the same with H-B-Chop-B-MPS. Detected output current and voltage at DigCon-MPS is converted as digital signal at precise ASDC board. DSP\&FPGA board is analysis of digital signal and generate IGBT gate driver. If output filter is not adopted, DigCon-MPS's switching noise is supplied to magnet. Therefore magnet is appeared noise spectrum associated with switching frequency as H-B-Chop-B-MPS. If especially designed output filter is adopted, DigConMPS's switching noise is not supplied to magnet. Therefore magnet is not appeared noise spectrum associated with switching frequency. DigCon-MPS is developed $25 \mathrm{kHz}$ switching frequency. Fig. 4 is frequency characteristics for no output filter at $5 \mathrm{~A}$ output current. In case of no applied output filter, multiplied frequency of switching frequency is appear at output current.

\footnotetext{
* Work suppory by MOST, KOREA
}

\# schkim@postech.ac.kr 


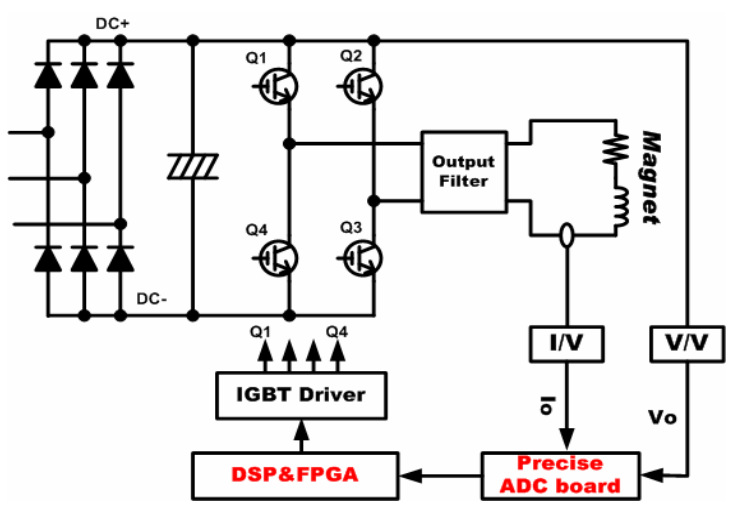

Figure 3: Configuration of DigCon-MPS.

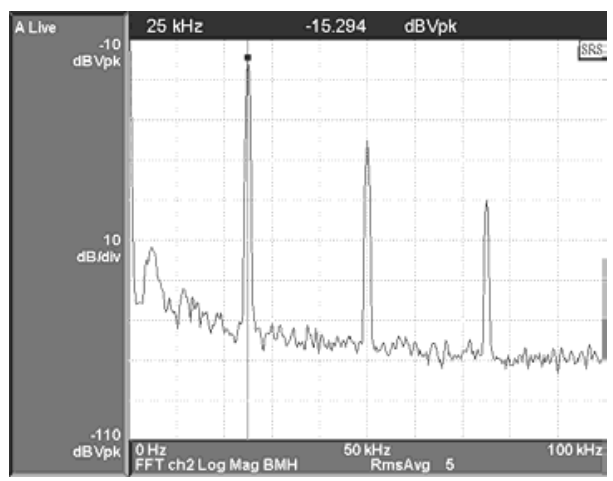

Figure 4: Frequency characteristics of DigCon-MPS for no filter case (5 A output).

\section{Output LC Filter design and fabrication for Dig-Con-MPS}

Output filter must be attenuation $-60 \mathrm{~dB}$ at over $25 \mathrm{kHz}$. A point of view SR beam orbit feedback, cut-off frequency must to be $4 \mathrm{kHz} \sim 5 \mathrm{kHz}$. Output filter is decided L-C-L-C second order type, and adopted damping element for low frequency. Fig. 5 shows output filter structure of DigCon-MPS.

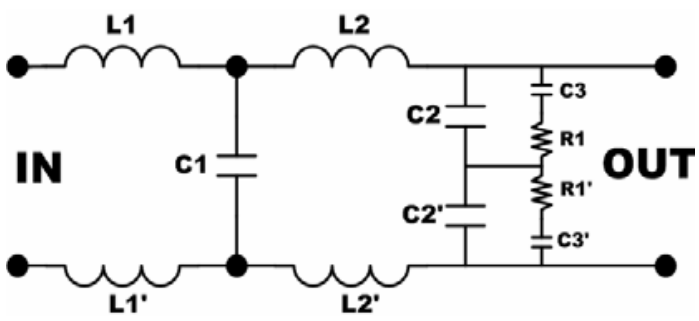

Figure 5: Shows output filter structure of DigCon-MPS.

To find parameters, we were use circuit simulation tool (IsSpice). Filter parameters are $\mathrm{L} 1\left(\mathrm{L1}^{\prime}\right)$ is $18 \mu \mathrm{F}, \mathrm{L} 2\left(\mathrm{~L}^{\prime}\right.$ ) is $12 \mu \mathrm{F}, \mathrm{C} 1$ is $25 \mu \mathrm{F}, \mathrm{C} 2\left(\mathrm{C} 2^{\prime}\right)$ is $35 \mu \mathrm{F}$, and $\mathrm{C} 3$ and $\mathrm{R} 1$ are $22 \mu \mathrm{F}$ and $50 \Omega$. Fig. 6 shows filter circuit simulation circuit. Fig. 7 shows filter circuit simulation result.

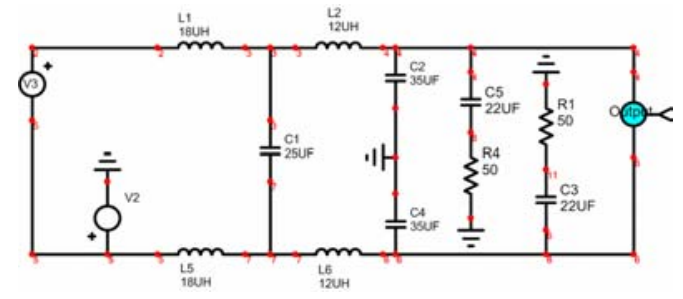

Figure 6: Filter circuit simulation circuit.

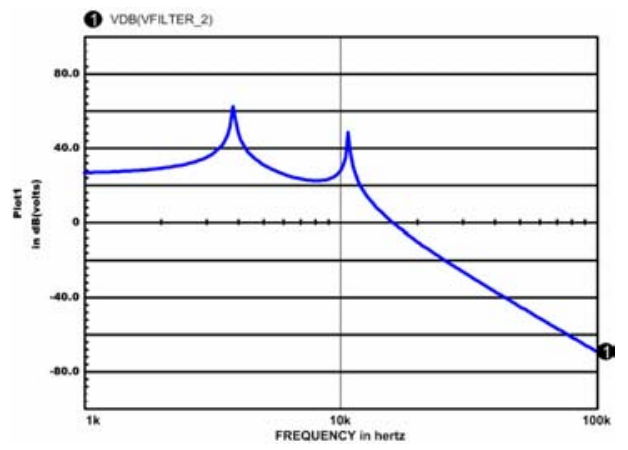

Figure 7: Filter circuit simulation result.

Inductors are fabricated by commercial E-E type ferrite core. $0.3 \mathrm{~mm}$ thickness 3 layer copper foil is utilized in winding.

\section{Frequency Characteristics of Output LC}

Dynamic signal analyser (SR780) is used for filter characteristics measurement. Input signal of the filter is used white noise signal and frequency characteristics measured at output. Fig. 8 shows set-up for filter characteristics measurement. Fig. 9 is frequency characteristics of filter. The filter characteristics is measured $4.5 \mathrm{kHz}$ cut-off frequency and is measured -90 $\mathrm{dB}$ attenuation at over $20 \mathrm{kHz}$.

\section{Output LC Filter effect at DigCon-MPS}

Filter effect at DigCon-MPS is compared with frequency measurement input and output of filter. A Frequency characteristic at filter output is not measured associated switching frequency. Fig. 10 shows filter effect at DigCon-MPS. Fig. 11, 12 and 13 are show output current characteristics of the DigCon-MPS for $0 \sim 800 \mathrm{~Hz}$, $0 \sim 12.8 \mathrm{kHz}$ and $0 \sim 25.6 \mathrm{kHz}$ at $5 \mathrm{~A}$ output.

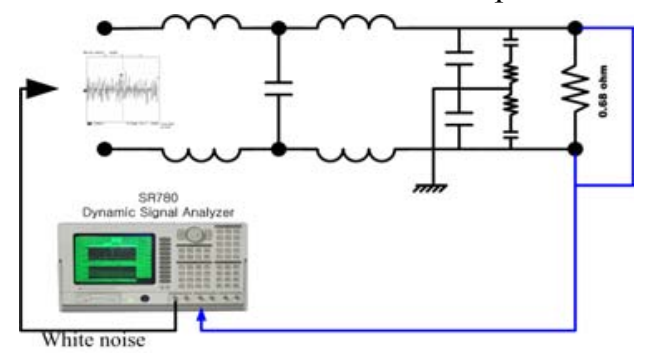

Figure 8: Set-up for filter characteristics measurement. 


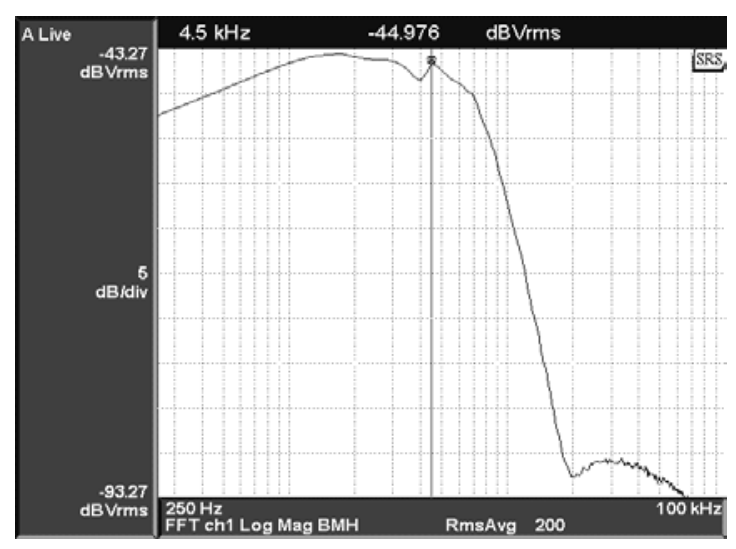

Figure 9: Frequency characteristics of filter.

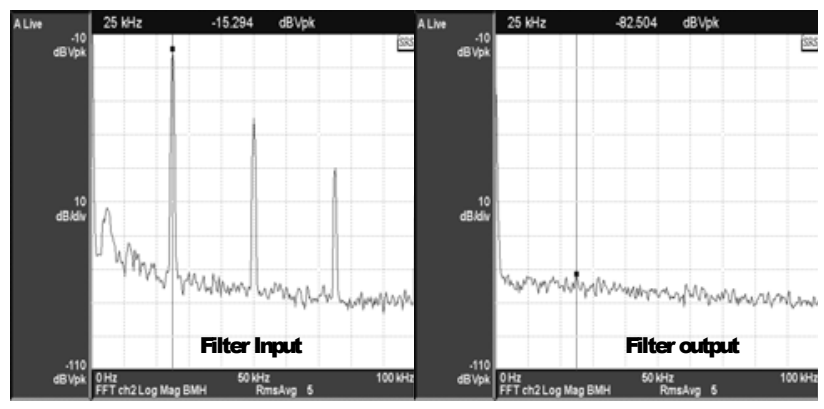

Figure 10: Output LC filter effect at DigCon-MPS.

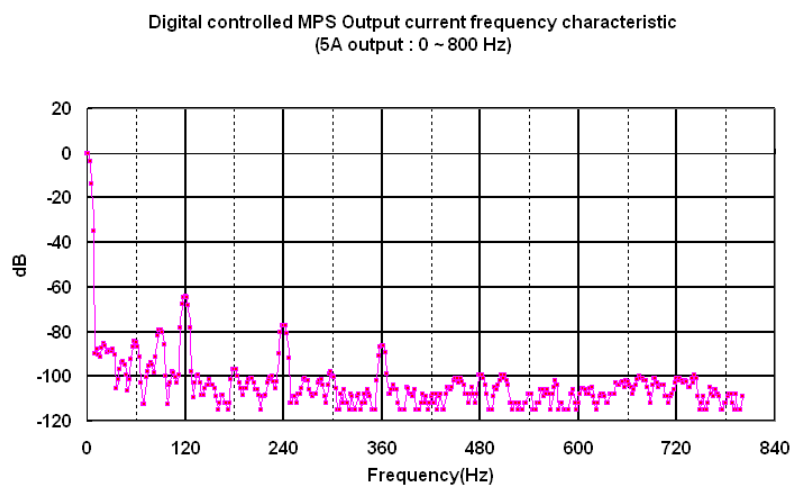

Figure 11: Output current characteristics of the DigConMPS for $0 \sim 800 \mathrm{~Hz}$ at $5 \mathrm{~A}$ output.

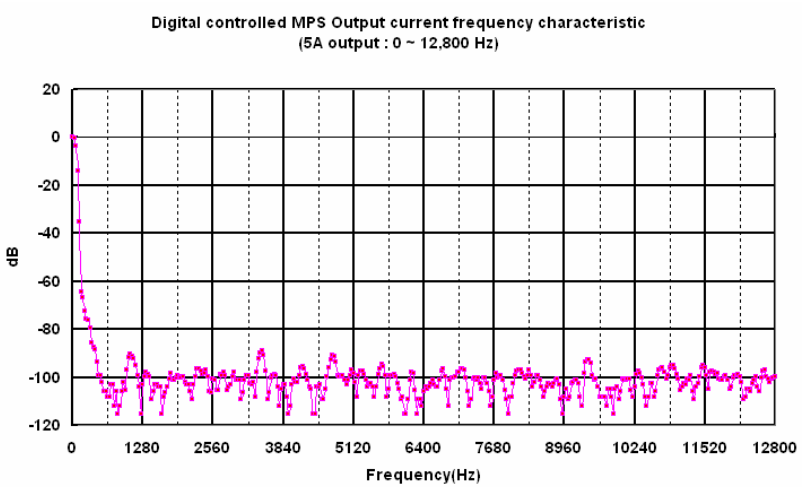

Figure 12: Output current characteristics of the DigConMPS for $0 \sim 12.8 \mathrm{kHz}$ at $5 \mathrm{~A}$ output.

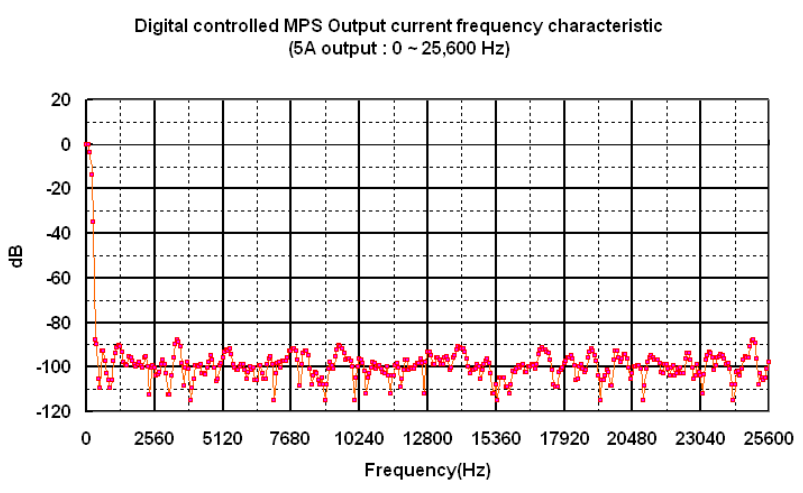

Figure 13: Output current characteristics of the DigConMPS for $0 \sim 25.6 \mathrm{kHz}$ at $5 \mathrm{~A}$ output.

\section{SUMMARY}

High accuracy and stability digital controlled power supply for magnet (DigCon-MPS) is developed at PLS. Output LC filter is developed as secondary order type. The filter characteristics is measured $4.5 \mathrm{kHz}$ cut-off frequencies and is measured $-90 \mathrm{~dB}$ attenuation at $>20$ $\mathrm{kHz}$. At DigCon-MPS adopted output filter, output current is eliminated all frequency except $120 \mathrm{~Hz} /-60 \mathrm{~dB}$, 240/-80dB and $360 \mathrm{~Hz} /-90 \mathrm{~dB}$.

\section{REFERENCE}

[1] J. H. Suh, etc, " Performance of the PLS high precision magnet power supplies", proceeding of LINAC2002, pp.503-505

[2] Erich Christian, LC Filters, Wiley-Interscience Pub.1983

[3] Mark J. Nave, Power Line Filter Design for switchmode power supplies, VAN NOSTRAND REINHOLD, 1991 